\title{
Salivary neuron specific enolase: an indicator for neuronal damage in patients with ischemic stroke and stroke-prone patients
}

\author{
Natheer H. Al-Rawi, ${ }^{1, *}$ and Karim M. Atiyah ${ }^{2}$ \\ ${ }^{1}$ College of Dentistry, University of Sharjah, \\ Sharjah, UAE \\ ${ }^{2}$ College of Medicine, Qadisiya University, Qadisiya, \\ Iraq
}

\begin{abstract}
Background: The blood-brain barrier is compromised in patients with stroke. The release of neuro-biochemical protein markers, such as neuron specific enolase (NSE) into the circulation may allow the pathophysiology and prognosis of patients with cerebrovascular diseases to be evaluated further. The present study was designed to measure the marker of neuronal damage, NSE, in saliva and serum of patients with acute ischemic stroke and patients with stroke related diseases as a diagnostic and/or monitoring tool for early prediction of ischemic stroke.

Methods: Salivary and serum NSE concentrations were measured in 150 individuals. Fifty were patients recently diagnosed as having ischemic stroke, 75 were gender and age-matched risk-group patients (patients with hypertension, type 2 diabetes and ischemic heart disease). Another 25 were gender and age-matched healthy controls.

Results: Salivary and serum NSE concentrations were significantly higher than that of healthy controls. The cut-off threshold for salivary NSE of $3.7 \mu \mathrm{g} / \mathrm{L}$ was optimum, showing $80 \%$ accuracy for differentiation of ischemic stroke from normal individuals.

Conclusions: Salivary NSE (alone or in combination with serum) can be used as a valuable diagnostic and possibly prognostic tool for measurement of neuronal damage in patients with stroke and stroke-related diseases.

Clin Chem Lab Med 2009;47:1519-24.
\end{abstract}

Keywords: cerebrovascular accident; neuron specific enolase; neuronal damage marker; saliva; stroke.

\section{Introduction}

Stroke or cerebrovascular accidents (CVA) are considered the third leading cause of death after cardiovascular diseases and cancer (1). The blood-brain barrier

*Corresponding author: Natheer H. Al-Rawi, Assistant Professor, College of Dentistry, University of Sharjah, Sharjah, UAE

E-mail: nhabdulla@yahoo.com

Received May 14, 2009; accepted July 30, 2009;

previously published online October 30, 2009 is compromised in patients with stroke, and the release of neuro-biochemical protein markers into the circulation may allow the pathophysiology and prognosis of patients with cerebrovascular diseases to be evaluated further (2). As a consequence of bloodbrain barrier disruption, antigens found either primarily or exclusively in the central nervous system (CNS), such as neuron specific enolase (NSE), may leak into the peripheral circulation (3). NSE is a soluble brain protein first described by Moore and McGregor in 1965 (4). NSE is a dimeric isoenzyme of the glycolytic enzyme enolase. It is found in the cytoplasm of neurons and cells of neuro-endocrine differentiation (5). The measurement of NSE concentrations in serum and cerebrospinal fluid (CSF) following cerebral ischemia and traumatic head injury provides a reliable laboratory indicator of the degree of brain cell damage, and may allow for early prediction of outcome $(6,7)$. In patients with stroke, the first NSE peak is found following admission, followed by a second increase between days $2-4$. The first NSE peak within 7-18 $\mathrm{h}$ following onset of stroke may reflect the initial damage to neuronal tissue, whereas the second increase may be attributed to secondary mechanisms of neuronal damage due to edema and an increase in intracranial pressure (3). Therefore, NSE concentrations can provide early information about neuronal damage.

Saliva is considered as an ultra filtrate of plasma (8). Diagnosis of diseases using analysis of saliva is potentially valuable for children and the elderly, since collection of fluid is associated with fewer compliance problems compared with the collection of blood or CSF. Furthermore, analysis of saliva may provide a cost-effective approach for screening large populations.

The present study was designed to measure NSE in saliva and serum of newly diagnosed patients with ischemic stroke and patients with stroke-related diseases as a diagnostic and/or monitoring tool for early prediction of ischemic stroke.

\section{Patients and methods}

One hundred and fifty individuals from the Al-Diwania province of Iraq were enrolled in this study. They were categorized into three groups:

The first group (study group) was comprised of 50 patients (24 males and 26 females) who were recently diagnosed clinically and radiographically (Brain CT-scan) as having ischemic stroke. Their age ranged from 45 to 75 years.

The second group (case control group) was comprised of 75 gender and age-matched patients and served as the con- 
trol or risk group. This group included 25 patients ( 12 males and 13 females) with hypertension, 25 patients ( 11 males and 14 females) with type 2 diabetes and 25 patients ( 11 males and 14 females) with ischemic heart disease (angina or myocardial infarction).

The third group (negative control) was comprised of 25 gender and age-matched healthy individuals (12 males and 13 females).

All individuals were evaluated by full medical history and clinical examination, with laboratory investigations to exclude any other systemic or local disease that may affect the parameters examined in this study. Oral and periodontal examination was done for each individual and any patient with symptoms and signs of any active oral inflammation, advanced periodontitis or severe gingivitis were excluded.

All participants gave informed consent and the study protocol was approved by the Local Ethics Committee of Al-Diwaniya general teaching hospital.

For NSE analysis: blood and saliva samples were taken from patients and healthy control following an overnight fast (8.00-9.00 am). For isolation of serum, $5 \mathrm{~mL}$ of blood was collected from each individual and centrifuged at $3000 \mathrm{rpm}$ at $4^{\circ} \mathrm{C}$ for $5 \mathrm{~min}$. The supernatant was aspirated and stored in tubes at $-20^{\circ} \mathrm{C}$ until analysis. Saliva samples were collected under restful and quiet circumstances. First, the mouth was flushed with $100 \mathrm{~mL}$ of distilled water and then

Table 1 Distribution of risk factors in patients with ischemic stroke.

\begin{tabular}{llllll}
\hline $\begin{array}{l}\text { Ischemic stroke } \\
\text { patients }\end{array}$ & \multicolumn{2}{l}{ Risk factors } & & & \\
\cline { 2 - 6 } & Hypertension & Diabetes mellitus & Heart diseases & Smoking & $\begin{array}{l}\text { Previous transient } \\
\text { ischemic attack }\end{array}$ \\
\hline Female & $18(43.9 \%)$ & $17(50 \%)$ & $9(60 \%)$ & $6(23.1 \%)$ & $4(50 \%)$ \\
Male & $23(56.1 \%)$ & $17(50 \%)$ & $6(40 \%)$ & $20(76.9 \%)$ & $4(50 \%)$ \\
\hline Total & $41 / 50(82 \%)$ & $34 / 50(68 \%)$ & $15 / 50(30 \%)$ & $26 / 50(52 \%)$ & $8 / 50(16 \%)$ \\
\hline
\end{tabular}

Table 2 Mean concentrations of NSE in serum and saliva of ischemic stroke, case controls and negative controls.

\begin{tabular}{|c|c|c|c|c|c|}
\hline & \multirow{2}{*}{$\begin{array}{l}\text { Cases } \\
\text { (Ischemic stroke) }\end{array}$} & \multicolumn{3}{|l|}{ Risk group } & \multirow{2}{*}{$\begin{array}{l}\text { Healthy } \\
\text { controls }\end{array}$} \\
\hline & & Hypertension & $\begin{array}{l}\text { Diabetes } \\
\text { mellitus }\end{array}$ & Heart diseases & \\
\hline \multicolumn{6}{|c|}{ Serum NSE concentration, $\mu \mathrm{g} / \mathrm{L}$} \\
\hline Range & $(7.9-27.2)$ & $(6.3-20)$ & $(7.4-44.1)$ & $(10.2-18.9)$ & $(5-12.9)$ \\
\hline Mean & 17 & 12.3 & 18.9 & 14 & 8.2 \\
\hline SD & 4.5 & 6.1 & 16.3 & 3.2 & 2.8 \\
\hline SE & 1 & 2.71 & 7.28 & 1.41 & 0.89 \\
\hline \multicolumn{6}{|c|}{$p($ ANOVA) for difference between 5 study groups $=0.01$} \\
\hline \multicolumn{6}{|c|}{$\begin{array}{l}p \text { (Bonferonni t-test) for difference in mean between } \\
\text { Cases (ischemic stroke) } \times \text { cases controls (hypertension) }=1[\mathrm{NS}] \\
\text { Cases (ischemic stroke) } \times \text { cases controls (diabetes mellitus) }=1[\mathrm{NS}] \\
\text { Cases (ischemic stroke) } \times \text { cases controls (heart diseases) }=1 \text { [NS }] \\
\text { Cases (ischemic stroke) } \times \text { healthy controls }=0.011\end{array}$} \\
\hline \multicolumn{6}{|c|}{$\begin{array}{l}\text { Cases controls (hypertension) } \times \text { cases controls (diabetes mellitus) }=1 \text { [NS] } \\
\text { Cases controls (hypertension) } \times \text { cases controls }(\text { heart diseases })=1[\mathrm{NS}] \\
\text { Cases controls (diabetes mellitus) } \times \text { cases controls (heart diseases) }=1 \text { [NS] }\end{array}$} \\
\hline \multicolumn{6}{|c|}{$\begin{array}{l}\text { Cases controls (hypertension) } \times \text { healthy controls }=1[\mathrm{NS}] \\
\text { Cases controls (diabetes mellitus) } \times \text { healthy controls }=0.044 \\
\text { Cases controls (heart diseases) } \times \text { healthy controls }=1 \text { [NS] }\end{array}$} \\
\hline \multicolumn{6}{|c|}{ Salivary NSE concentration, $\mu \mathrm{g} / \mathrm{L}$} \\
\hline Range & $(2.3-8)$ & $(2.6-4.1)$ & $(2.7-3.9)$ & $(2.7-4)$ & $(2.2-3.5)$ \\
\hline Mean & 4.5 & 3.3 & 3.2 & 3.3 & 2.9 \\
\hline SD & 1.6 & 0.6 & 0.5 & 0.5 & 0.5 \\
\hline SE & 0.35 & 0.29 & 0.21 & 0.24 & 0.17 \\
\hline \multicolumn{6}{|c|}{$p$ (ANOVA) for difference between 5 study groups $=0.006$} \\
\hline \multicolumn{6}{|c|}{$\begin{array}{l}p \text { (Bonferonni t-test) for difference in mean between } \\
\text { Cases (ischemic stroke) } \times \text { cases controls (hypertension) }=0.4[\mathrm{NS}] \\
\text { Cases (ischemic stroke) } \times \text { cases controls (diabetes mellitus) }=0.23[\mathrm{~N} \\
\text { Cases (ischemic stroke) } \times \text { cases controls (heart diseases) }=0.4[\mathrm{NS}] \\
\text { Cases (ischemic stroke) } \times \text { healthy controls }=0.009\end{array}$} \\
\hline \multicolumn{6}{|c|}{$\begin{array}{l}\text { Cases controls (hypertension) } \times \text { cases controls (diabetes mellitus) }=1 \text { [NS] } \\
\text { Cases controls (hypertension) } \times \text { cases controls (heart diseases) }=1 \text { [NS] } \\
\text { Cases controls (diabetes mellitus) } \times \text { cases controls }(\mathrm{HD})=1[\mathrm{NS}]\end{array}$} \\
\hline \multicolumn{6}{|c|}{$\begin{array}{l}\text { Cases controls (hypertension) } \times \text { healthy controls }=1[\mathrm{NS}] \\
\text { Cases controls (diabetes mellitus) } \times \text { healthy controls }=1[\mathrm{NS}] \\
\text { Cases controls (heart diseases) } \times \text { healthy controls }=1[\mathrm{NS}]\end{array}$} \\
\hline
\end{tabular}


whole saliva was collected for 5 min by the subject leaning forward and spiting saliva into test tubes that were kept in crushed ice. Immediately following collection, samples were centrifuged at $3000 \mathrm{rpm}$ at $4^{\circ} \mathrm{C}$ for $5 \mathrm{~min}$. The supernatant was aspirated and stored at $-20^{\circ} \mathrm{C}$ until analysis.

The Can Ag NSE EIA kit (Ref 420-10 Fujirebio Diagnostic Inc, Goteborg, Sweden) was used in this study. Monoclonal antibodies (MABs) bind to the $\gamma$-subunit of NSE, allowing detection of both the $\gamma \gamma$ and the $\alpha \gamma$ form. Calibrators and patient samples were incubated with biotinylated anti-NSE MABE21 and horse radish peroxidase (HRP)-labeled antiNSE MABE17 in streptavidin coated microtiter strips, for $1 \mathrm{~h}$ with shaking. After washing, buffered substrate/chromogen reagent (hydrogen peroxide and 3,3,5,5-tetramethylbenzidine) was added to each well and the enzyme reaction allowed to proceed. Blue color developed if antigen was present and the color intensity was proportional to the amount of NSE present in the sample. The color intensity was determined using a microtiter plate spectrophotometer at $405 \mathrm{~nm}$. A calibration curve was constructed by plotting the absorbance value for each NSE calibrator against the corresponding NSE concentration of each calibrator (in $\mu \mathrm{g} / \mathrm{L})$. NSE concentrations in patients samples were determined from the calibration curve.

All data were analyzed using SPSS statistical package (SPSS, Version 15, Chicago, IL, USA). Data were expressed as mean \pm standard deviation (SD). Differences between groups were analyzed for significance using a one-way ANOVA. To discriminate between ischemic stroke cases and case-controls, and to compare the diagnostic performance of the test, receiver operating characteristic (ROC) curve analysis was used. Statistical significance was defined as $\mathrm{p}<0.05$.

\section{Results}

The mean age for patients with ischemic stroke was 58.2 years. Forty-one (82\%) were hypertensive, 34 were diabetic, 26 were heavy smokers and eight had a previous transient ischemic attack (Table 1). Since

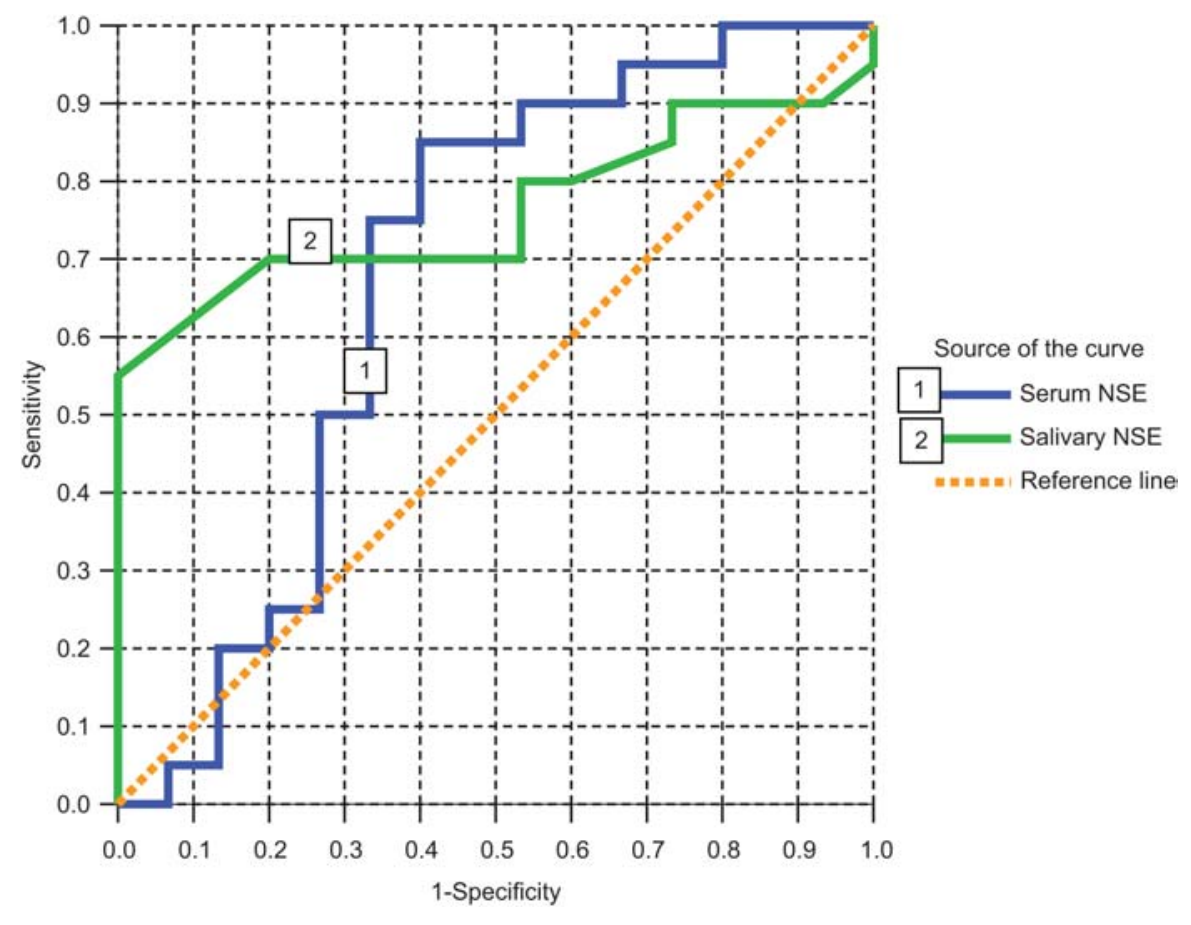

Figure 1 ROC curves for neuron specific enolase (NSE) used to diagnose ischemic stroke and differentiate patients from controls.

Serum NSE concentration ( $\mu \mathrm{g} / \mathrm{L}$ ): ROC area, $0.677 ; p=0.08$ (ns). Salivary NSE concentration ( $\mu \mathrm{g} / \mathrm{L})$ : $\mathrm{ROC}$ area, $0.763 ; p=0.008$.

Table 3 Parameters of neuron specific enolase (NSE) when used (positive if $\geq$ cut-off value) to diagnose ischemic stroke and differentiate patients from controls.

\begin{tabular}{|c|c|c|c|c|c|c|}
\hline $\begin{array}{l}\text { Positive if } \\
\geq \text { cut-off } \\
\text { value }\end{array}$ & $\begin{array}{l}\text { Sensitivity, } \\
\%\end{array}$ & $\begin{array}{l}\text { Specificity, } \\
\%\end{array}$ & $\begin{array}{l}\text { Accuracy, } \\
\%\end{array}$ & $\begin{array}{l}\text { PPV\% at pretest } \\
\text { probability }=50 \%\end{array}$ & $\begin{array}{l}\text { PPV\% at pretest } \\
\text { probability }=90 \%\end{array}$ & $\begin{array}{l}\text { NPV\% at pretest } \\
\text { probability }=10 \%\end{array}$ \\
\hline \multicolumn{7}{|c|}{ Serum NSE concentration, $\mu \mathrm{g} / \mathrm{L}$} \\
\hline 7.8 & 100.0 & 20.0 & 65.7 & 55.6 & 91.8 & 100.0 \\
\hline 14.9 & 75.0 & 66.7 & 71.4 & 69.3 & 95.3 & 96.0 \\
\hline 27.0 & 5.0 & 93.3 & 42.8 & 42.7 & 87.0 & 89.8 \\
\hline \multicolumn{7}{|c|}{ Salivary NSE concentration, $\mu \mathrm{g} / \mathrm{L}$} \\
\hline 2.7 & 90.0 & 6.7 & 54.3 & 49.1 & 89.7 & 85.8 \\
\hline 4.2 & 55.0 & 100.0 & 74.3 & 100.0 & 100.0 & 95.2 \\
\hline
\end{tabular}

PPV, positive predictive value; NPV, negative predictive value. 


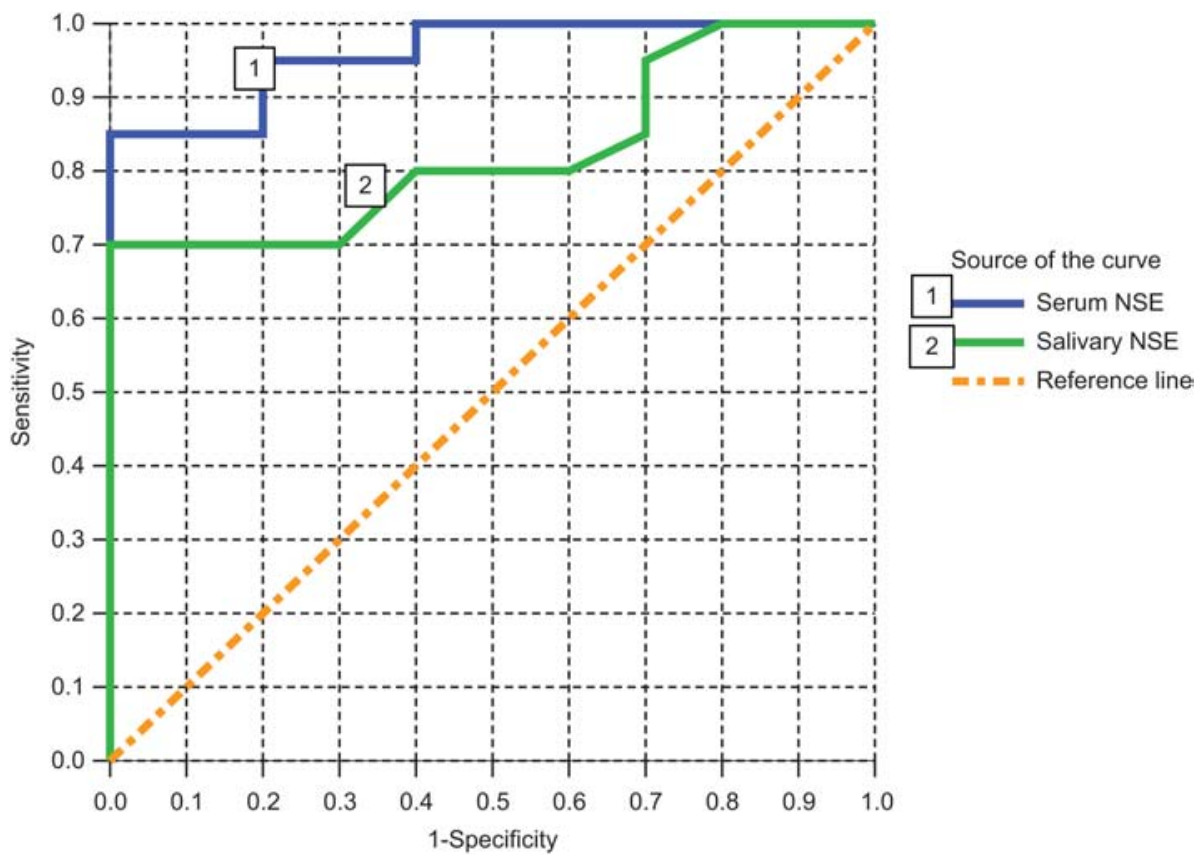

Figure 2 ROC curves for neuron specific enolase (NSE) used to diagnose ischemic stroke and differentiate patients from negative controls.

Serum NSE concentration ( $\mu \mathrm{g} / \mathrm{L})$ : ROC area, $0.96 ; p<0.001$. Salivary NSE concentration ( $\mu \mathrm{g} / \mathrm{L})$ : ROC area, $0.825 ; p=0.004$.

Table 4 Parameters of neuron specific enolase (NSE) when used (positive if $\geq$ cut-off value) to diagnose ischemic stroke and differentiate patients from negative controls.

\begin{tabular}{|c|c|c|c|c|c|c|}
\hline $\begin{array}{l}\text { Positive if } \\
\geq \text { cut-off } \\
\text { value }\end{array}$ & $\begin{array}{l}\text { Sensitivity, } \\
\%\end{array}$ & $\begin{array}{l}\text { Specificity, } \\
\%\end{array}$ & $\begin{array}{l}\text { Accuracy, } \\
\%\end{array}$ & $\begin{array}{l}\text { PPV\% at pretest } \\
\text { probability }=50 \%\end{array}$ & $\begin{array}{l}\text { PPV\% at pretest } \\
\text { probability }=90 \%\end{array}$ & $\begin{array}{l}\text { NPV\% at pretest } \\
\text { probability }=10 \%\end{array}$ \\
\hline \multicolumn{7}{|c|}{ Serum NSE concentration, $\mu \mathrm{g} / \mathrm{L}$} \\
\hline 7.8 & 100.0 & 60.0 & 86.7 & 71.4 & 95.7 & 100.0 \\
\hline 13.1 & 85.0 & 100.0 & 90.0 & 100.0 & 100.0 & 98.4 \\
\hline \multicolumn{7}{|c|}{ Salivary NSE concentration, $\mu \mathrm{g} / \mathrm{L}$} \\
\hline 2.3 & 100.0 & 20.0 & 73.3 & 55.6 & 91.8 & 100.0 \\
\hline 3.7 & 70.0 & 100.0 & 80.0 & 100.0 & 100.0 & 96.8 \\
\hline
\end{tabular}

the concentrations of NSE in serum and saliva did not vary with age and gender, the results from males and females were grouped together.

Mean serum NSE concentrations were significantly higher than those in healthy controls $(17.00 \pm 4.5 \mathrm{vs}$. $8.2 \pm 2.80 \mu \mathrm{g} / \mathrm{L})$. However, concentrations were not significantly different from those seen in hypertensive, diabetic patients as well as patients with ischemic heart diseases (Table 2).

Diabetic patients had significantly higher serum NSE concentrations than healthy controls. However, patients with hypertension and patients with ischemic heart diseases did not show any significant difference in serum NSE concentrations when compared with those in healthy controls (Table 2).

Salivary NSE concentrations showed higher NSE values in patients with ischemic stroke compared to healthy controls $(4.5 \pm 1.6$ vs. $2.9 \pm 0.5 \mu \mathrm{g} / \mathrm{L})$. Salivary NSE in patients with ischemic stroke did not show any significant difference when compared with the risk group patients (Table 2).
ROC curve analysis was used to show the trade-off between sensitivity and specificity for different cut-off values of NSE when used to diagnose ischemic stroke and differentiate these patients from the risk group (Figure 1 and Table 3).

The area under ROC curve for salivary NSE was significantly higher $(0.763)(p=0.008)$ compared to serum NSE (0.677). For salivary NSE, the optimum cut-off value was $(4.2 \mu \mathrm{g} / \mathrm{L})$. This value yielded optimum specificity $(100 \%)$ and reasonable sensitivity (55\%).

ROC curve analysis was also applied for differentiating cases with ischemic stroke from healthy controls (Figure 2 and Table 4). The area under the ROC curve for serum NSE was significantly higher (0.960) $(p<0.001)$ compared to salivary NSE $(0.825)$. The optimum cut-off value for serum NSE showing the highest diagnostic accuracy $(90 \%)$ was $(\geq 13.1 \mu \mathrm{g} / \mathrm{L})$. This cut-off threshold showed optimum specificity (100\%) and reasonable sensitivity $(85 \%)$. For salivary NSE, the optimum cut-off value showing the highest diag- 
nostic accuracy $(80 \%)$ was ( $\geq 3.7 \mu \mathrm{g} / \mathrm{L})$. This cut-off threshold showed optimum specificity $(100 \%)$ and reasonable sensitivity $(70 \%)$.

\section{Discussion}

Stroke remains the third leading cause of death and the second most frequent cause of morbidity in developed countries. Ischemic stroke accounts for $80 \%$ of all strokes (9). Ischemia causes a cascade of events that eventually lead to neuronal damage and cell death (10). NSE is the predominant enolase found in neural tissue, and the structural characteristics of this enolase allow for greater stability in high chloride concentrations compared with enolases in other organ systems (6). Physiologically, NSE is present in negligible amounts in the peripheral blood. DeGiorgio et al. (7) stated that "the measurement of NSE concentrations in serum and CSF following cerebral ischemia and traumatic head injury provides a reliable laboratory indicator of the degree of brain cell damage, and may allow early prediction of prognostic outcome". NSE has been used as a serum and CSF marker of neuronal damage in conditions, such as head injury, status epilepticus, Creutzfeld-Jackob's disease, multi-infarct dementia, brain metastases, subarachnoid hemorrhage and stroke $(11,12)$. In the present study, serum NSE concentrations that are reported are in accordance with those reported by others $(13,14)$. After acute CNS insult, such as cerebral infarction, hypoxia, trauma and seizure, the blood-brain barrier is altered and astroglial disintegration results in leakage of NSE into the CSF and serum $(3,15)$. In the present investigation, no statistically significant difference was found between patients with ischemic stroke and at risk patients. However, the concentrations of serum NSE in diabetic patients, only, were similar to those seen in patients with ischemic stroke, which was significantly increased. This indicated that diabetic patients showed some sort of neuronal damage and/or bloodbrain barrier disruption. This finding was in agreement with Hovsepyan et al. (16) who demonstrated a significant increase in antibodies against NSE in both type 1 and type 2 diabetic subjects compared to healthy controls. In hypertensive patients and patients with ischemic heart diseases, the mean serum NSE ranked an intermediate values between ischemic stroke and healthy controls. This may be explained due to the fact that patients with hypertension and patients with ischemic heart diseases may also be associated, to a lesser extent, with alterations in the integrity of the blood-brain barrier. This can explain the increased serum NSE concentrations in these patients. Serum NSE was not an accurate predictor of ischemic stroke in the "at risk" group of patients. However, serum NSE with an optimum cut-off value $(\geq 13.1 \mu \mathrm{g} / \mathrm{L}$ ) is helpful in differentiating patients with ischemic stroke from healthy controls. NSE was also detected in human saliva. To our knowledge, this study is the first to investigate the presence of NSE in saliva. In the healthy control group, mean salivary concentrations were $2.9 \pm 0.5 \mu \mathrm{g} / \mathrm{L}$, with a range between 2.2-3.5 $\mu \mathrm{g} / \mathrm{L}$. This indicated the presence of NSE in trace amounts in the saliva of healthy individuals. Salivary NSE was increased in patients with ischemic stroke and stroke-prone patients. This makes salivary NSE, using an optimum cut-off value of $\geq 4.2 \mu \mathrm{g} / \mathrm{L}$, diagnostic in predicting ischemic stroke in stroke-prone individuals. The presence of NSE in saliva of patients with ischemic stroke and "at risk" patients may be explained by the fact that the integrity of the blood-brain barrier is disrupted to various degrees in these patients, and leakage of this enzyme outside the CNS can be seen in salivary secretion.

\section{Conclusions}

NSE is present in human saliva and may be of use as a diagnostic, and possible prognostic tool, for assessing neuronal damage in patients with stroke and stroke-related diseases.

\section{Conflict of interest statement}

There was not any conflict of interest.

\section{Acknowledgements}

The authors would like to thank the staff of Central Laboratories in Al-Diwania Hospital for their help in performing the laboratory tests for the patients.

\section{References}

1. Thorvaldsen $P$, Kuulasmaa $K$, Rajakangas $A$, Rastenyte $D$, Sarti C, Wilhelmsen L. Stroke trends in the WHO MONICA project. Stroke 1997;28:500-6.

2. Stevens $H$, Jakobs $C$, de Jager $A E$, Cunningham RT, Korf $\mathrm{J}$. Neuron-specific enolase and $\mathrm{N}$-acetyl-aspartate as potential peripheral markers of ischemic stroke. Eur J Clin Invest 1999;29:6-11.

3. Wunderlich MT, Elbert AD, Kratz T, Goertlerr M, Jost $S$, Herman M. Early neurobehavioral outcome after stroke is related to release of neurobiochemical markers of brain damage. Stroke 1999;30:1190-5.

4. Kaiser E, Kuzmits R, Pregant $P$, Burghuber O, Worofka W. Clinical biochemistry of neuron specific enolase. Clin Chim Acta 1989;183:13-31.

5. Barone FC, Clark RK, Price WJ, White RF, Feuerstein GZ, Storer BL, et al. Neuron-specific enolase increases in cerebral and systemic circulation following focal ischemia. Brain Res 1993;623:77-82.

6. Bonner JA, Sloan JA, Rowland KM, Klee GG, Kugler JW, Mailliard JA, et al. Significance of neuron specific enolase levels before and during therapy of small cell lung cancer. Clin Cancer Res 2000;6:597-601.

7. DeGiorgio CM, Gott PS, Rabinowicz AL, Heck CN, Smith TD, Correale JD, et al. Neuron-specific enolase, a marker of acute neuronal injury, is increased in complex partial status epilepticus. Epilepsia 1996;37:606-9. 
8. Ritschel WA, Thompson GA. Monitoring of drug concentrations in saliva: a non-invasive pharmacokinetic procedure. Method Find Exp Clin Pharmacol 1983;5:511-25.

9. Bonita R, Stewart A, Beaglehole R. International trends in stroke mortality: 1970-1985. Stroke 1990;21:989-92.

10. Fisher M, Schaebitz W. An overview of acute stroke therapy. Past, present, and future. Arch Intern Med 2000;160: 3196-206.

11. Mokuno K, Kato K, Kawai K, Matsuoka Y, Yanagi T, Sobue I. Neuron-specific enolase and S-100 protein levels in cerebrospinal fluid of patients with various neurological diseases. J Neurol Sci 1983;60:443-51.

12. Skogseid IM, Nordby HK, Urdal P, Paus E, Lilleaas F. Increased serum creatine kinase BB and neuron-specific enolase following head injury indicates brain damage. Acta Neurochir (Wien) 1992;115:106-11.
13. Nygaard O, Langbakk B, Romner B. Neuron-specific enolase concentrations in serum and cerebrospinal fluid in patients with no previous history of neurological disorder. Scand J Clin Lab Invest 1998;58:183-6.

14. Casmiro M, Maitan S, De Pasquale F, Cova V, Scarpae E, Vignatelli L. Cerebrospinal fluid and serum neuronspecific enolase concentrations in a normal population. Eur J Neurol 2005;12:369-74.

15. Missler U, Wiesmann M, Friedrich C, Kaps M. S-100 protein and neuron-specific enolase concentrations in blood as indicators of infarction volume and prognosis in acute ischemic stroke. Stroke 1997;28:1956-60.

16. Hovsepyan MR, Haas MJ, Boyojyan AS, Guevorkyan AA, Mamikonyan AA, Myers SE, et al. Astrocytic and neuronal biochemical markers in the sera of subjects with diabetes mellitus. Neuroscience 2004;369:224-7. 